\title{
BMJ Open Investigating the effect of sociodemographic factors on 30-day hospital readmission among medical patients in Toronto, Canada: a prospective cohort study
}

\author{
Robert W Smith, ${ }^{1}$ Kerry Kuluski, ${ }^{2,3}$ Andrew P Costa, ${ }^{4}$ Samir K Sinha, ${ }^{2,5,6}$ \\ Richard H Glazier, ${ }^{7,8}$ Alan Forster, ${ }^{9,10}$ Lianne Jeffs ${ }^{2,11}$
}

To cite: Smith RW,

Kuluski K, Costa AP, et al. Investigating the effect of sociodemographic factors on 30-day hospital readmission among medical patients in Toronto, Canada: a prospective cohort study. BMJ Open 2017;7:e017956. doi:10.1136/ bmjopen-2017-017956

- Prepublication history and additional material for this paper are available online. To view these files, please visit the journal online (http://dx.doi. org/10.1136/bmjopen-2017017956).

Received 2 June 2017 Revised 10 0ctober 2017 Accepted 9 November 2017

CrossMark

For numbered affiliations see end of article.

Correspondence to Mr Robert W Smith; robert.smith@ndph.ox.ac.uk

\section{ABSTRACT}

Objective To examine the influence of patient-level sociodemographic factors on the incidence of hospital readmission within 30 days among medical patients in a large Canadian metropolitan city.

Design Prospective cohort study.

Setting and participants Patients admitted to the General Internal Medicine service of an urban teaching hospital in Toronto, Canada participated in a survey of sociodemographic information. Patients were not surveyed if deemed medically unstable, receiving care in medical/ surgical step-down beds or were isolated for infection control. Included in the final analysis was a diverse cohort of 1427 adult, non-palliative, patients who were discharged home.

Measures Thirteen patient-level sociodemographic variables were examined in relation to time to unplanned all-cause readmission within 30 days. Illness level was accounted for by the following covariates: self-perceived health status, previous hospital utilisation, primary diagnosis case mix group, Charlson Comorbidity Index score and inpatient length of stay.

Results Approximately, $14.4 \%(n=205)$ of patients experienced readmission within 30 days. Sociodemographic factors were not significantly associated with time to readmission in unadjusted and adjusted analyses. Indicators of illness level, namely, previous hospitalisations, were the strongest risk factors for readmission within this cohort. One previous admission (adjusted HR 1.78; 95\% Cl 1.22 to 2.59, $\mathrm{P}<0.01)$ and at least four previous emergency department visits (adjusted HR 2.33; 95\% Cl 1.46 to $4.43, \mathrm{P}<0.01$ ) were associated with increased hazard of readmission within 30 days.

Conclusions Patient-level sociodemographic factors did not influence the incidence of unplanned all-cause readmission within 30 days. Further research is needed to understand the generalisability of our findings and investigate whether contextual factors, such as access to universal health insurance coverage, attenuate the effects of sociodemographic factors.
Strengths and limitations of this study

- Our study represents the first detailed examination of patient-level sociodemographic factors in relation to hospital readmission within a general medical patient population in Canada.

- The sample size was robust; however, despite this, multicategory sociodemographic variables required aggregation.

- Survey methods reduced the likelihood of nonresponse from marginalised groups; however, the proportion of missing data was particularly high for total family income.

- The generalisability of these findings to other communities within and beyond Toronto, Canada, remains unclear.

\section{INTRODUCTION}

Unplanned hospital readmissions occurring within 30 days of discharge are considered to be adverse health outcomes that are common, harmful to patients, costly to the health system and to some degree preventable. $^{1-3}$ The causal mechanisms leading to hospital readmissions are complex and not well understood. ${ }^{4}$ Risk factors for readmission that are commonly substantiated within medical patient populations include characteristics of a person's medical condition and pre-existing comorbidities, historical healthcare utilisation and characteristics of the medical care delivered in hospital and shortly after discharge. ${ }^{5-10}$

Several studies have examined how risk of readmission is influenced by social and demographic characteristics of people and the communities within which they live. ${ }^{16-8} 11-25$ Sociodemographic factors are believed to influence how individuals use healthcare by predisposing them to illness, affecting their 


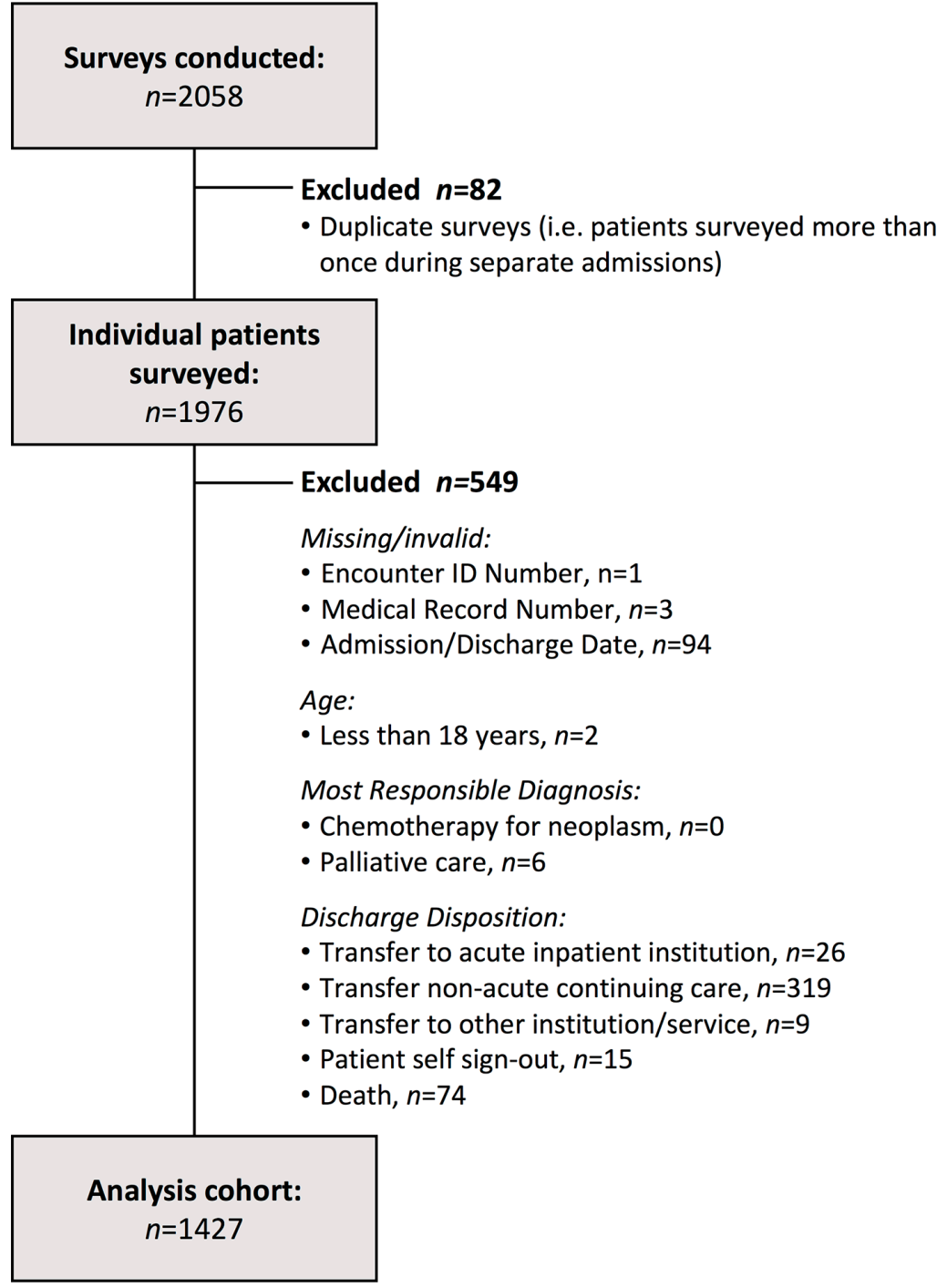

Figure 1 Cohort derivation procedures and final sample size.

intentions on and ability to access healthcare and affecting their perceived and professionally evaluated need for healthcare.$^{26}$ Due in part to data availability limitations, sociodemographic factors such as age, gender/sex and neighbourhood-level indicators of socioeconomic status have garnered the greatest attention within this literature. Few studies have examined the effects of a variety of less commonly investigated patient-level sociodemographic factors such as the following: total family income, education, housing situation, race, language, place of birth, sexual orientation, religious/spiritual affiliation and disability. A stronger understanding of these relationships may inform the design of healthcare delivery models and health policy aimed at preventing readmissions and reducing health inequities.

Systematic collection and utilisation of patient-level sociodemographic data is not a widespread practice within health systems such as Canada's. ${ }^{27}$ In 2012, the Measuring Health Equity programme was initiated by three downtown hospitals and the public health unit in Toronto, Canada, to develop a standardised process for, and initiate the collection of detailed patient-level sociodemographic information. ${ }^{28} 29$

We sought to understand whether and to what degree patient-level sociodemographic factors influence the incidence of hospital readmission over a 30-day time frame within an urban Canadian medical patient population.

\section{METHODS}

\section{Study design and data sources}

We conducted a prospective cohort study involving 1976 patients admitted to the General Internal Medicine (GIM) service of a 442-bed academic health sciences centre in Toronto. As part of the Measuring Health Equity programme, consenting patients were surveyed by trained research personnel and staff between June 2012 and July 2014. Surveys questions (see table 1 in the online Supplementary file 1) were translated in 11 languages and professional interpreters were available for patients who were not comfortable completing the survey in English. Five days per week, research personnel screened 
GIM service admitted patient lists to identify candidates for survey participation. Before the identified candidates were approached at the bedside, research personnel consulted with clinical staff to ensure the patients were in stable enough condition to give informed consent and participate in the survey. Patients were not surveyed if actively receiving care in intensive or critical care units, medical/surgical step-down beds or isolated for infection control purposes. Among those who were approached by research staff, we estimate that $75 \%$ of eligible patients or their proxies provided written informed consent to participate. This estimated response rate was calculated as of July 2013. Due to inconsistencies in survey administration from July 2013, a final response rate for the sampled population was not attainable.

Survey data were linked to medical record data from the Canadian Institute for Health Information (CIHI) Discharge Abstract Database (DAD) and National Ambulatory Care Reporting System (NACRS). DAD and NACRS provided information related to characteristics of each patient's inpatient admissions and emergency department (ED) visits (eg, admission/discharge dates, diagnoses, clinical service providers, discharge disposition).

\section{Study cohort derivation}

Figure 1 presents the cohort derivation process. We focused on adults admitted to the GIM service and discharged to the community. Surveyed patients were excluded if their records exhibited the following: missing patient identification numbers; missing admission, discharge and birth dates; age was under 18 years; most responsible diagnosis codes indicated palliative care or chemotherapy for neoplasm; patient was not discharged to their place of residence (ie, home or non-institutional home setting with and without support services like home care); or discharge disposition indicated death or patient self-sign out. These exclusion criteria are consistent with those used by CIHI to calculate 30-day medical readmission rates and derive the Hospital Admission Risk Prediction (HARP) index study cohort. ${ }^{730}$ However, we did not exclude patients whose primary reason for admission was related to obstetric or mental health conditions and those who received surgical interventions during their index admission. Few patients within the sample exhibited these characteristics, and it was hypothesised that their inclusion would better reflect the clinically diverse patient population served on medical units. Also, these patients were assessed by physicians, and their diagnoses were deemed appropriate for care on the GIM service as opposed to solely obstetric, psychiatric or surgical units. The final sample size was 1427 patients.

\section{Outcome variable}

The outcome variable was time to first unplanned, all-cause readmission to any acute care hospital within the Toronto Central Local Health Integration Network region. Approximately, 1.2 million people reside in this region. The observation window extended 30 days following the index discharge date. The patient was the unit of analysis. Only subsequent admissions that were classified as urgent/emergent (ie, unplanned, non-elective) were considered. To align with prior research, we considered subsequent admissions readmissions including when the discharge disposition of this subsequent encounter indicated death. ${ }^{13}$

\section{Sociodemographic variables and covariates}

Variable selection was guided by an extensive review of previous observational studies examining risk factors for readmission among medical patients and Andersen's behavioural model. ${ }^{26}{ }^{31}$ The behavioural model is a conceptual framework for the determinants of healthcare utilisation. It considers contextual, individual, behavioural and health outcome factors. For example, affecting whether someone accesses hospital care may include the following: contextual characteristics of the communities where they live (ie, policies governing the organisation of and access to healthcare and social welfare programmes); an individual's sociodemographic characteristics, health status and lifestyle; and the medical care processes and health outcomes experienced upon accessing care. Andersen's latest adaptation of the behavioural model was chosen for its relevance to the comprehensive study of sociodemographic, behavioural, health related and contextual determinants of healthcare utilisation. ${ }^{26}$ Due to the patient-level nature of the available data, our study focused on individual characteristics. These predisposing, enabling and need factors are posited to influence how individuals use healthcare by predisposing them to illness, affecting their intentions on and ability to access healthcare and affecting their perceived and professionally evaluated need for healthcare. ${ }^{26}$

We examined patient-level sociodemographic factors as predisposing, enabling and need factors. The following independent variables were conceptualised as predisposing factors: age, gender, sexual orientation, race, place of birth, religious/spiritual affiliation, primary spoken and reading languages, self-perceived ability to speak and understand English, educational attainment. Sexual orientation was the only variable for which no previous medical readmission studies could be identified. This variable was included because of recent data from the Canadian Community Health Survey indicating potential differences in access to regular medical care and healthcare-seeking behaviour among those who identify as homosexual and bisexual compared with heterosexual. ${ }^{32}$ Total family income, home ownership and discharge disposition (ie, receipt of home care services) were conceptualised as enabling factors. The following variables were conceptualised as need factors: self-perceived health status and disabilities, frequency of ED visits and inpatient admissions 6 months preceding a patient's index admission date, primary diagnosis case mix group, Charlson Comorbidity Index score and inpatient length of stay. Self-reported disabilities were analysed as a disability score variable representing the total number of 
physical, sensory, learning and developmental disabilities and or disability related to chronic illness, mental health or drug or alcohol dependence. The categorical structure of previous hospitalisation and primary diagnosis variables were based on a readmission risk prediction algorithm recently derived and validated among medical patients in Ontario, Canada. ${ }^{7}$ Charlson scores were calculated according to the latest scoring scheme. ${ }^{33}$ To promote comparability of results with previous research, inpatient length of stay was studied as a median value. ${ }^{13}$ The structure of categorical need factor variables aggregation was informed by previous research. ${ }^{734}$ For statistical power, the categories of sociodemographic variables were combined to maintain at least 50 patients in each category. Each variable is defined in detail within table 1 in the online supplementary file 1 .

\section{Missing data}

Patients were included in the analyses if they did not respond to every question of the survey. Given the sensitive nature of the information, it was probable that "prefer not to answer' (PNA), 'do not know' (DK) and complete non-responses were not missing at random. For this reason, imputation was not used to manage missing data. Alternatively, PNA and DK responses were aggregated into one category for each sociodemographic variable and included in regression analyses. Since it was unclear why some patients had complete non-responses recorded as opposed to PNA/DK responses, these patients were not included in the regression analyses.

\section{Statistical analysis}

Kaplan-Meier product-limit failure plots were used to assess the absolute probability of readmission over the 30-day observation window. Univariate and multivariable Cox regression was used to examine associations between independent variables and time to readmission. Patients who did not experience readmission were censored at 30 days. HRs were calculated at a 95\% CI level to measure the magnitude and direction of effects. The proportional hazards assumption was assessed by modelling time-dependent covariates for each independent variable and covariate. This assumption was satisfied. Primary reading language and English proficiency exhibited evidence of multicollinearity and were thus not included in multivariable analyses. Anticipating a $14 \%$ to $15 \%$ readmission rate within this cohort, we estimated that each multivariable model had adequate statistical power to examine 19 to 21 variables. All statistical analyses were conducted using SAS software V.9.4. ${ }^{35}$

\section{RESULTS}

Table 1 presents the descriptive characteristics of our study sample. Approximately, 14.4\% ( $\mathrm{n}=205)$ of patients experienced readmission within 30 days. One-third of readmissions occurred within the first 7 days. The mean time to readmission was 12.4 days $(\mathrm{SD}=8.46)$.
The median age of patients in this cohort was 67 years (IQR 50 to 81 ). The majority identified as female $(\mathrm{n}=771,54 \%)$, white-European $(\mathrm{n}=988,69 \%)$ and heterosexual $(\mathrm{n}=1279,90 \%)$. Approximately $80 \%$ of patients $(\mathrm{n}=1138)$ felt most comfortable speaking with their healthcare provider in English. Collectively, however, patients within this sample comfortably spoke and read at least 28 different languages and identified with at least 12 racial groups. About half $(n=696,49 \%)$ of the cohort was not born in Canada. Many patients preferred not to disclose or did not know their annual total family income $(\mathrm{n}=661,46 \%)$. Among those that did, the most common category reported was income less than $\$ C 20000$ ( $n=204$, $14 \%)$. The majority reported attaining at least some postsecondary education $(\mathrm{n}=808,57 \%)$ and living in accommodations that they did not own $(n=755,53 \%)$. Approximately half the cohort rated their general health as at least good (ie, good, very good or excellent; $n=709$, $50 \%)$. The majority reported experiencing at least one disability $(\mathrm{n}=781,55 \%)$. Most did not experience an ED visit $(\mathrm{n}=989,69 \%)$ or inpatient admission $(\mathrm{n}=1211,85 \%)$ 6 months prior to the index admission. The three most common diagnoses primarily responsible for admission were the following: pneumonia $(n=59,4.1 \%)$, symptom/ sign of the digestive system $(\mathrm{n}=47,3.3 \%)$ and heart failure $(n=43,3.0 \%)$. The median number of recorded comorbidities was 2 (IQR 1 to 3 ). However, relatively few patients exhibited one or more Charlson comorbidities $(15 \%, \mathrm{n}=208)$.

Unadjusted and adjusted Cox regression analyses did not substantiate significant associations between predisposing or enabling factors and unplanned all-cause hospital readmission within 30 days (table 2). Among need factors, fair (unadjusted HR 1.52; 95\% CI 2.09 to 2.12, $\mathrm{P}=0.01$ ) and poor (unadjusted HR 1.61;95\% CI 1.14 to $2.27, \mathrm{P}=0.01$ ) self-perceived health were associated with increased hazard of readmission in unadjusted models but were no longer significantly associated after controlling for all other variables. Previous ED visits and inpatient admissions were also significantly associated with readmission in unadjusted models, however, remaining significant within the adjusted model, were one previous inpatient admission (adjusted HR 1.78; 95\% CI 1.22 to 2.59, $\mathrm{P}<0.01$ ) and at least four previous ED visits (adjusted HR 2.33; 95\% CI 1.46 to $4.43, \mathrm{P}<0.01)$.

\section{DISCUSSION}

Our prospective study of 1427 patients admitted to the GIM service of an urban teaching hospital in Toronto, Canada, represents the first detailed examination of patient-level sociodemographic factors in relation to hospital readmission within a general Canadian medical patient population. Predisposing and enabling sociodemographic factors were not significantly associated with unplanned all-cause hospital readmission within 30 days. Need factors, namely previous hospital utilisation, were significantly associated with increased hazard of readmission. These findings 
Table 1 Characteristics of the analysis cohort and observed readmissions

\begin{tabular}{|c|c|c|c|}
\hline \multirow[b]{2}{*}{$\begin{array}{l}\text { Individual } \\
\text { characteristics }\end{array}$} & \multirow{2}{*}{$\begin{array}{l}\text { Overall } \\
\text { cohort } \\
\text { of patients } \\
(n=1427)\end{array}$} & \multicolumn{2}{|c|}{$\begin{array}{l}\text { Unplanned all-cause } \\
\text { readmission within } \\
30 \text { days, of patients }\end{array}$} \\
\hline & & $\begin{array}{l}\text { No } \\
(n=1222) \\
(85.6 \%)\end{array}$ & $\begin{array}{l}\text { Yes }(n=205) \\
(14.4 \%)\end{array}$ \\
\hline \multicolumn{4}{|l|}{ Predisposing factors } \\
\hline \multicolumn{4}{|l|}{ Age } \\
\hline Median (IQR) & $67(50-81)$ & $68(51-82)$ & $67(49-88)$ \\
\hline $18-64$ & $45.1 \%$ & $44.8 \%$ & $46.3 \%$ \\
\hline $65-84$ & $36.6 \%$ & $36.5 \%$ & $37.1 \%$ \\
\hline $85+$ & $18.4 \%$ & $18.7 \%$ & $16.6 \%$ \\
\hline \multicolumn{4}{|l|}{ Gender } \\
\hline Female & $54.0 \%$ & $53.8 \%$ & $55.6 \%$ \\
\hline Male & $43.5 \%$ & $43.8 \%$ & $42.0 \%$ \\
\hline Transgender/PNA/DK & $2.1 \%$ & $2.1 \%$ & $2.1 \%$ \\
\hline \multicolumn{4}{|l|}{ Sexual orientation } \\
\hline Heterosexual & $89.6 \%$ & $89.5 \%$ & $90.2 \%$ \\
\hline Not Heterosexual & $4.3 \%$ & $4.6 \%$ & $2.9 \%$ \\
\hline PNA/DK & $5.7 \%$ & $5.5 \%$ & $6.8 \%$ \\
\hline \multicolumn{4}{|l|}{ Race } \\
\hline White-European & $69.2 \%$ & $68.8 \%$ & $71.7 \%$ \\
\hline Asian & $11.1 \%$ & $10.9 \%$ & $12.2 \%$ \\
\hline Black & $5.5 \%$ & $5.9 \%$ & $3.4 \%$ \\
\hline Not Asian/Black/White & $10.7 \%$ & $10.9 \%$ & $9.3 \%$ \\
\hline PNA/DK & $3.2 \%$ & $3.1 \%$ & $3.4 \%$ \\
\hline
\end{tabular}

Religious/spiritual affiliation

$\begin{array}{llll}\text { Affiliation } & 75.1 \% & 74.7 \% & 77.6 \% \\ \text { No affiliation } & 19.8 \% & 20.0 \% & 18.0 \% \\ \text { PNA/DK } & 4.7 \% & 4.8 \% & 4.4 \%\end{array}$

Place of birth

$\begin{array}{llll}\text { Canada } & 49.5 \% & 49.6 \% & 48.8 \% \\ \text { Not Canada } & 48.8 \% & 48.5 \% & 50.2 \% \\ \text { PNA } & 1.4 \% & 1.5 \% & 1.0 \%\end{array}$

Primary spoken language

$\begin{array}{llll}\text { English } & 79.7 \% & 80.5 \% & 75.1 \% \\ \text { Non-English } & 18.3 \% & 17.4 \% & 23.4 \% \\ \text { PNA/DK } & 1.6 \% & 1.7 \% & 1.5 \%\end{array}$

Primary reading language

\begin{tabular}{llll} 
English & $80.7 \%$ & $81.2 \%$ & $78.0 \%$ \\
Not English & $17.4 \%$ & $16.9 \%$ & $20.5 \%$ \\
\hline PNA/DK & $1.5 \%$ & $1.5 \%$ & $1.5 \%$
\end{tabular}

Self-perceived ability to speak/understand English

$\begin{array}{llll}\text { Well } & 86.1 \% & 86.3 \% & 85.4 \% \\ \text { Not well } & 11.2 \% & 11.0 \% & 12.2 \% \\ \text { PNA/DK } & 2.3 \% & 2.3 \% & 2.0 \%\end{array}$

Highest level of education
Table 1 Continued

\begin{tabular}{|c|c|c|c|}
\hline \multirow[b]{2}{*}{$\begin{array}{l}\text { Individual } \\
\text { characteristics }\end{array}$} & \multirow{2}{*}{$\begin{array}{l}\text { Overall } \\
\text { cohort } \\
\text { of patients } \\
(n=1427)\end{array}$} & \multicolumn{2}{|c|}{$\begin{array}{l}\text { Unplanned all-cause } \\
\text { readmission within } \\
30 \text { days, of patients }\end{array}$} \\
\hline & & $\begin{array}{l}\text { No } \\
(n=1222) \\
(85.6 \%)\end{array}$ & $\begin{array}{l}\text { Yes }(n=205) \\
(14.4 \%)\end{array}$ \\
\hline Some high school & $18.5 \%$ & $18.4 \%$ & $19.0 \%$ \\
\hline High school diploma & $18.9 \%$ & $18.7 \%$ & $20.5 \%$ \\
\hline $\begin{array}{l}\text { At least some } \\
\text { postsecondary }\end{array}$ & $56.6 \%$ & $57.4 \%$ & $52.2 \%$ \\
\hline Other/PNA/DK & $5.5 \%$ & $5.1 \%$ & $7.8 \%$ \\
\hline \multicolumn{4}{|l|}{ Enabling factors } \\
\hline \multicolumn{4}{|l|}{ Total family income group } \\
\hline US\$19999 and less & $14.3 \%$ & $14.2 \%$ & $14.6 \%$ \\
\hline US\$20 000-US\$39999 & $12.4 \%$ & $12.7 \%$ & $10.7 \%$ \\
\hline US\$40 000-US\$59999 & $7.6 \%$ & $7.5 \%$ & $8.3 \%$ \\
\hline US\$60 000-US\$99999 & $8.1 \%$ & $8.2 \%$ & $7.8 \%$ \\
\hline US\$100000 and over & $10.9 \%$ & $10.7 \%$ & $11.7 \%$ \\
\hline PNA/DK & $46.3 \%$ & $46.2 \%$ & $46.9 \%$ \\
\hline \multicolumn{4}{|l|}{ Home ownership } \\
\hline Home owner & $43.9 \%$ & $43.5 \%$ & $45.9 \%$ \\
\hline Not home owner & $52.9 \%$ & $53.2 \%$ & $51.2 \%$ \\
\hline PNA/DK & $2.9 \%$ & $2.9 \%$ & $2.9 \%$ \\
\hline \multicolumn{4}{|l|}{ Discharge disposition } \\
\hline Home without services & $65.1 \%$ & $66.0 \%$ & $59.5 \%$ \\
\hline Home with services & $34.9 \%$ & $34.0 \%$ & $40.5 \%$ \\
\hline Need factors & & & \\
\hline
\end{tabular}

Disability score

$\begin{array}{llll}0 & 38.3 \% & 38.5 \% & 36.6 \% \\ 1 & 37.8 \% & 37.7 \% & 38.0 \% \\ 2+ & 17.0 \% & 16.7 \% & 18.5 \% \\ \text { PNA/DK } & 6.6 \% & 6.7 \% & 6.9 \%\end{array}$

Self-perceived general health

$\begin{array}{llll}\text { Good } & 49.7 \% & 51.3 \% & 40.0 \% \\ \text { Fair } & 24.6 \% & 23.8 \% & 29.3 \% \\ \text { Poor } & 21.1 \% & 20.2 \% & 26.3 \% \\ \text { PNA/DK } & 4.2 \% & 4.3 \% & 4.0 \%\end{array}$

Inpatient admissions previous 6 months

$\begin{array}{llll}0 & 84.9 \% & 86.5 \% & 75.1 \% \\ 1 & 11.4 \% & 10.1 \% & 19.0 \% \\ 2 & 2.2 \% & 2.2 \% & 2.4 \% \\ 3+ & 1.5 \% & 1.1 \% & 3.4 \%\end{array}$

Emergency department visits previous 6 months

\begin{tabular}{llll}
0 & $69.3 \%$ & $71.3 \%$ & $57.6 \%$ \\
1 & $17.3 \%$ & $16.8 \%$ & $20.5 \%$ \\
2 & $5.3 \%$ & $4.8 \%$ & $8.3 \%$ \\
3 & $2.4 \%$ & $2.5 \%$ & $1.5 \%$ \\
$4+$ & $5.7 \%$ & $4.6 \%$ & $12.2 \%$ \\
\hline
\end{tabular}

Continued

Continued 
Table 1 Continued

\begin{tabular}{|c|c|c|c|}
\hline \multirow[b]{2}{*}{$\begin{array}{l}\text { Individual } \\
\text { characteristics }\end{array}$} & \multirow{2}{*}{$\begin{array}{l}\text { Overall } \\
\text { cohort } \\
\text { of patients } \\
(n=1427)\end{array}$} & \multicolumn{2}{|c|}{$\begin{array}{l}\text { Unplanned all-cause } \\
\text { readmission within } \\
30 \text { days, of patients }\end{array}$} \\
\hline & & $\begin{array}{l}\text { No } \\
(n=1222) \\
(85.6 \%)\end{array}$ & $\begin{array}{l}\text { Yes }(n=205) \\
(14.4 \%)\end{array}$ \\
\hline \multicolumn{4}{|c|}{ Case mix group of most responsible diagnosis } \\
\hline $\begin{array}{l}\text { Heart failure without } \\
\text { cardiac catheterisation }\end{array}$ & $3.0 \%$ & $2.7 \%$ & $4.9 \%$ \\
\hline $\begin{array}{l}\text { Chronic obstructive } \\
\text { pulmonary disease }\end{array}$ & $2.7 \%$ & $3.0 \%$ & $1.0 \%$ \\
\hline $\begin{array}{l}\text { Inflammatory bowel } \\
\text { disease }\end{array}$ & $2.7 \%$ & $2.8 \%$ & $2.0 \%$ \\
\hline Diabetes & $1.8 \%$ & $2.0 \%$ & $0.5 \%$ \\
\hline $\begin{array}{l}\text { Gastrointestinal } \\
\text { obstruction }\end{array}$ & $0.8 \%$ & $0.8 \%$ & $1.0 \%$ \\
\hline $\begin{array}{l}\text { Cirrhosis/alcoholic } \\
\text { hepatitis }\end{array}$ & $0.8 \%$ & $0.7 \%$ & $1.5 \%$ \\
\hline $\begin{array}{l}\text { All other case mix } \\
\text { groups }\end{array}$ & $88.1 \%$ & $87.9 \%$ & $89.3 \%$ \\
\hline \multicolumn{4}{|l|}{ Charlson score } \\
\hline$>0$ & $14.6 \%$ & $13.8 \%$ & $19.0 \%$ \\
\hline \multicolumn{4}{|c|}{ Index admission length of stay } \\
\hline Median (IQR) & $5(3-8)$ & $5(3-8)$ & $5(3-8)$ \\
\hline
\end{tabular}

DK, do not know; PNA, prefer not to answer.

are largely consistent with previous research involving medical patients. ${ }^{6} 8$ 12-14 17213637 However, contrasting findings from previous research remain compelling as they may provide insight into contexts within which sociodemographic factors predispose individuals to risk of, and or enable, hospital readmissions. Our findings also have clinical, policy and research implications which merit discussion.

Our findings support previous research suggesting that many patient-level sociodemographic factors likely do not independently influence hospital readmission risk among medical patients. It remains possible, however, that sociodemographic factors vary in their effects on recovery and disease self-management depending a person's specific medical condition. Indeed, studies analysing patients hospitalised for heart failure and pneumonia tend to substantiate lower socioeconomic status and black race as risk factors for readmission. ${ }^{11}$ Such patterns are not apparent among general medical patient populations. Some sociodemographic variables may also be sensitive to effect moderation by unmeasured contextual factors. According to Andersen's behavioural model, healthcare utilisation is affected by contextual characteristics of the communities within which people live and the health system from which people seek care. ${ }^{26}$ Access to comprehensive social safety net and universal publicly funded health insurance programmes, for example, may attenuate associations between socioeconomic enabling factors and readmission within nations such as Canada ${ }^{13}$ and France. ${ }^{37}$ Medicare and Medicaid programmes in the USA may not mitigate readmission risk associated with a patient's socioeconomic circumstances to the same extent. ${ }^{1217}$ This could be attributed to differences in the adequacy of coverage and quality of health and social services accessible to Medicare and Medicaid beneficiaries compared with beneficiaries of universal publicly funded health insurance programmes. There also exists evidence for $^{2136}$ and against ${ }^{81217}$ predisposing factors such as race/ethnicity and primary spoken language as risk factors for readmission among medical patients. Contributing to these mixed findings may be contextual differences across study sites related to the cultural competence of care providers and as suggested by Karliner and colleagues ${ }^{21}$ the availability of interpreters and translated patient education materials. Further research is needed to understand whether and to what degree contextual factors influence readmission risk and whether they moderate the effects of predisposing and enabling factors. Much like approaches being taken in the $\mathrm{USA}^{38}$; this research should aspire to mixed methodologies examining how sociodemographic factors intersect among themselves and with other clinical factors to influence recovery during and shortly after hospitalisation.

Consistent with previous research, need factors such as ED visits and hospital admissions preceding the index admission were the strongest indicators of readmission risk. ${ }^{5812}$ Need factors related to disability ${ }^{1439} 40$ and comorbidity ${ }^{15} 1736$ have previously been linked to readmission among medical patients. Measurement error may account for our non-significant findings in relation to these need factors and among specific levels of the previous hospitalisation variables.

A criticism of policies aimed at incentivising quality improvement and reducing readmission rates in the USA is that hospitals serving more socially disadvantaged patient populations are disproportionately penalised for readmission rates above their expected target. ${ }^{41}$ Within a Canadian context, patient-level sociodemographic factors may not explain a significant degree of variation in 30-day medical readmission rates within and between regions. As such, many of the predisposing and enabling factors we examined may not be suitable for targeting high-risk patients for intervention or for the risk adjustment of health system quality indicators such as 30-day readmission rates. In the absence of empirical and conceptual evidence of association between a specific sociodemographic variable and a quality indicator, genuine differences in the quality of care can be obscured and become more difficult to remediate. ${ }^{42}$

The detailed patient-level nature of sociodemographic data that were analysed is a noteworthy strength of this study. These data elucidated in detail the sociodemographic diversity of medical patients within Toronto, Canada. Patient-level data is ideal for studying health inequalities and discerning inequity. ${ }^{27}$ As opposed to geocoded neighbourhood-level sociodemographic data, patient-level data 
Table 2 Results of unadjusted and adjusted Cox regression analyses examining predisposing, enabling and need factors in relation to 30-day unplanned all-cause readmission

\begin{tabular}{lllll}
\hline Individual characteristics & Unadjusted HR (95\% Cl) & P value & Fully adjusted HR (95\% Cl) & P value \\
\hline Predisposing factors & & & & \\
Age & & & Reference & \\
\hline $18-64$ & Reference & 0.86 & $0.83(0.59$ to 1.17$)$ & 0.28 \\
\hline $65-84$ & $0.97(0.72$ to 1.32$)$ & 0.46 & $0.71(0.45$ to 1.12$)$ & 0.14 \\
\hline $85+$ & $0.86(0.58$ to 1.28$)$ & &
\end{tabular}

Gender*

\begin{tabular}{lllll} 
Female & Reference & & Reference & \\
\hline Male & $0.93(0.70$ to 1.23$)$ & 0.60 & $0.98(0.73$ to 1.31$)$ & 0.88 \\
\hline $\begin{array}{l}\text { Transgender/PNA/DK } \\
\text { Sexual orientation* }\end{array}$ & $1.15(0.47$ to 2.81$)$ & 0.76 & $2.00(0.55$ to 7.21$)$ & 0.29 \\
\hline Heterosexual & Reference & & & \\
\hline Not heterosexual & $0.66(0.30$ to 1.50$)$ & 0.32 & $0.58(0.25$ to 1.36$)$ & 0.21 \\
\hline PNA/DK & $1.22(0.71$ to 2.10$)$ & 0.48 & $0.95(0.47$ to 1.91$)$ & 0.88
\end{tabular}

Race

\begin{tabular}{lllll} 
White-European & Reference & & Reference & 0.58 \\
Asian & $1.08(0.70$ to 1.64$)$ & 0.73 & $0.87(0.54$ to 1.41$)$ & 0.13 \\
\hline Black & $0.57(0.27$ to 1.22$)$ & 0.15 & $0.54(0.24$ to 1.20$)$ & 0.50 \\
Not Asian/Black/White & $0.83(0.52$ to 1.35$)$ & 0.46 & $0.84(0.51$ to 1.38$)$ & 0.42 \\
\hline PNA/DK & $1.04(0.49$ to 2.22$)$ & 0.92 & $1.47(0.58$ to 3.74$)$ &
\end{tabular}

Religious/spiritual affiliation*

$\begin{array}{lllll}\text { Affiliation } & \text { Reference } & & \text { Reference } & \\ \text { No affiliation } & 0.89(0.62 \text { to } 1.27) & 0.51 & 0.95 \text { (0.65 to } 1.39) & 0.80 \\ \text { PNA/DK } & 0.89(0.45 \text { to } 1.74) & 0.73 & 0.94 \text { (0.43 to } 2.07) & 0.89\end{array}$

Place of birth

$\begin{array}{lllll}\text { Canada } & \text { Reference } & & \text { Reference } & \\ \text { Not Canada } & 1.04(0.79 \text { to } 1.36) & 0.80 & 0.98 \text { (0.69 to } 1.40) & 0.92 \\ \text { PNA/DK } & 0.68(0.17 \text { to } 2.73) & 0.59 & 0.17(0.01 \text { to } 2.30) & 0.18\end{array}$

Primary spoken language*

\begin{tabular}{|c|c|c|c|c|}
\hline English & Reference & & Reference & \\
\hline Non-English & 1.39 (1.00 to 1.92$)$ & 0.05 & $1.29(0.86$ to 1.93$)$ & 0.23 \\
\hline PNA/DK & 0.93 (0.30 to 2.18$)$ & 0.90 & 0.99 (0.18 to 5.36$)$ & 0.99 \\
\hline \multicolumn{5}{|l|}{ Primary reading language* } \\
\hline English & Reference & & - & - \\
\hline Not English & 1.24 (0.88 to 1.74$)$ & 0.22 & - & - \\
\hline PNA/DK & 0.98 (0.31 to 3.06$)$ & 0.97 & - & - \\
\hline \multicolumn{5}{|c|}{ Self-perceived ability to speak/understand English $\dagger$} \\
\hline Well & Reference & & - & - \\
\hline Not well & 1.11 (0.73 to 1.69$)$ & 0.63 & - & - \\
\hline PNA/DK & 0.89 (0.33 to 2.39$)$ & 0.81 & - & - \\
\hline \multicolumn{5}{|l|}{ Highest level of education† } \\
\hline Some high school & 1.13 (0.78 to 1.63$)$ & 0.52 & 1.08 (0.71 to 1.64$)$ & 0.72 \\
\hline High school diploma & 1.19 (0.83 to 1.69$)$ & 0.35 & 1.23 (0.84 to 1.80$)$ & 0.28 \\
\hline At least some postsecondary & Reference & & Reference & \\
\hline Other/PNA/DK & 1.61 (0.95 to 2.73$)$ & 0.07 & 1.72 (0.92 to 3.23$)$ & 0.09 \\
\hline
\end{tabular}

Continued 
Open Access

Table 2 Continued

\begin{tabular}{|c|c|c|c|c|}
\hline Individual characteristics & Unadjusted HR (95\% Cl) & $P$ value & Fully adjusted HR $(95 \% \mathrm{Cl})$ & $P$ value \\
\hline \multicolumn{5}{|l|}{ Enabling factors } \\
\hline \multicolumn{5}{|l|}{ Total family income group } \\
\hline 1-US\$19999 and less & 0.94 (0.55 to 1.61$)$ & 0.83 & 0.70 (0.38 to 1.29$)$ & 0.26 \\
\hline 2-US\$20 000-\$39999 & 0.79 (0.44 to 1.40$)$ & 0.41 & 0.78 (0.42 to 1.45$)$ & 0.43 \\
\hline $3-U S \$ 40000-\$ 59999$ & 1.01 (0.54 to 1.87$)$ & 0.99 & 0.94 (0.49 to 1.80$)$ & 0.86 \\
\hline 4-US\$60 000-\$99999 & 0.89 (0.47 to 1.67$)$ & 0.71 & 0.93 (0.49 to 1.76$)$ & 0.82 \\
\hline $5-$ US $\$ 100000$ and over & Reference & & Reference & \\
\hline PNA/DK & 0.94 (0.60 to 1.46$)$ & 0.77 & 0.82 (0.50 to 1.34$)$ & 0.42 \\
\hline \multicolumn{5}{|l|}{ Home ownership* } \\
\hline Home owner & Reference & & Reference & \\
\hline Not home owner & 0.92 (0.70 to 1.22$)$ & 0.58 & 1.00 (0.73 to 1.37$)$ & 0.99 \\
\hline PNA/DK & 0.96 (0.42 to 2.19$)$ & 0.92 & $0.93(0.31$ to 2.81$)$ & 0.89 \\
\hline \multicolumn{5}{|l|}{ Discharge disposition } \\
\hline Home without services & Reference & & Reference & \\
\hline Home with services & 1.28 (0.97 to 1.70$)$ & 0.08 & 1.07 (0.78 to 1.48$)$ & 0.67 \\
\hline
\end{tabular}

\section{Need factors}

Disability score*

\begin{tabular}{|lllll}
\hline 0 & Reference & & Reference & \\
\hline 1 & $1.06(0.78$ to 1.46$)$ & 0.70 & $0.97(0.69$ to 1.37$)$ & 0.88 \\
\hline $2+$ & $1.16(0.79$ to 1.72$)$ & 0.45 & $1.20(0.77$ to 1.85$)$ & 0.42 \\
\hline PNA/DK & $1.07(0.60$ to 1.89$)$ & 0.82 & $1.00(0.53$ to 1.90$)$ & 0.99 \\
\hline $\begin{array}{l}\text { Self-perceived general health† } \\
\text { Good }\end{array}$ & Reference & & Reference & \\
\hline Fair & $1.52(1.09$ to 2.12$)$ & 0.01 & $1.39(0.98$ to 1.98$)$ & 0.07 \\
\hline Poor & $1.61(1.14$ to 2.27$)$ & 0.01 & $1.15(0.77$ to 1.72$)$ & 0.49 \\
\hline PNA/DK & $1.28(0.65$ to 2.56$)$ & 0.48 & $1.02(0.46$ to 2.27$)$ & 0.97 \\
\hline Inpatient admissions previous 6 months & & & & \\
\hline 0 & Reference & & Reference & $<0.01$ \\
\hline 1 & $2.01(1.41$ to 2.85$)$ & $<0.01$ & $1.78(1.22$ to 2.59$)$ & 0.65 \\
\hline 2 & $1.23(0.50$ to 2.99$)$ & 0.65 & $1.03(0.41$ to 2.58$)$ & 0.08 \\
\hline $3+$ & $2.96(1.39$ to 6.32$)$ & 0.01 & $2.06(0.93$ to 4.58$)$ &
\end{tabular}

Emergency department visits previous 6 months

\begin{tabular}{|c|c|c|c|c|}
\hline 0 & Reference & & Reference & \\
\hline 1 & 1.44 (1.01 to 2.04$)$ & 0.04 & 1.41 (0.98 to 2.04$)$ & 0.06 \\
\hline 2 & 1.98 (1.19 to 3.29$)$ & 0.01 & $1.62(0.95$ to 3.29$)$ & 0.08 \\
\hline 3 & 0.73 (0.23 to 2.30$)$ & 0.59 & $0.63(0.20$ to 2.30$)$ & 0.59 \\
\hline $4+$ & 2.88 (1.89 to 4.43$)$ & $<0.01$ & 2.33 (1.46 to 4.43$)$ & $<0.01$ \\
\hline \multicolumn{5}{|c|}{ Case mix group of most responsible diagnosis } \\
\hline $\begin{array}{l}\text { Heart failure without cardiac } \\
\text { catheterisation }\end{array}$ & 1.63 (0.86 to 3.08$)$ & 0.13 & $1.70(0.87$ to 3.31$)$ & 0.12 \\
\hline Chronic obstructive pulmonary disease & 0.34 (0.08 to 1.36$)$ & 0.13 & 0.36 (0.09 to 1.49$)$ & 0.16 \\
\hline Inflammatory bowel disease & $0.70(0.26$ to 1.90$)$ & 0.49 & 0.86 (0.31 to 2.38$)$ & 0.77 \\
\hline Diabetes & 0.25 (0.04 to 1.79$)$ & 0.17 & 0.24 (0.03 to 1.78$)$ & 0.16 \\
\hline Gastrointestinal obstruction & 1.09 (0.27 to 4.41$)$ & 0.90 & 1.33 (0.32 to 5.54$)$ & 0.69 \\
\hline Cirrhosis/alcoholic hepatitis & 1.78 (0.57 to 5.58$)$ & 0.32 & 1.49 (0.45 to 4.94$)$ & 0.52 \\
\hline
\end{tabular}


Table 2 Continued

\begin{tabular}{|c|c|c|c|c|}
\hline Individual characteristics & Unadjusted HR (95\% Cl) & $P$ value & Fully adjusted HR $(95 \% \mathrm{Cl})$ & $P$ value \\
\hline All other case mix groups & Reference & & Reference & \\
\hline \multicolumn{5}{|l|}{ Charlson score } \\
\hline $1+$ & 1.39 (0.98 to 1.97$)$ & 0.07 & $1.34(0.92$ to 1.94$)$ & 0.13 \\
\hline \multicolumn{5}{|l|}{ Inpatient length of stay } \\
\hline
\end{tabular}

${ }^{*} n=1422$ observations used within univariate model.

$\mathrm{tn}=1421$ observations used within univariate model.

$n=1427$ observations were analysed in each univariate model and $n=1420$ in multivariable models unless otherwise indicated.

Primary reading language and English proficiency exhibited evidence of multicollinearity and were thus not included in the multivariable analyses.

DK, do not know; PNA, prefer not to answer.

is less vulnerable to misclassification. However, limitations associated with the collection and analysis of patient-level data within our study merit consideration.

Based on early survey records, we estimated that $75 \%$ of patients approached by research staff participated in the Measuring Health Equity survey. However, the exact number and nature of patients who declined were not available. Affecting the generalisability of our findings may be non-response, response and recall bias. Post hoc descriptive analyses of previous population-based studies involving medical patients from Canada $^{13}$ and Mount Sinai Hospital admissions data suggest that the clinical characteristics of our sample were largely reflective of medical patients discharged home at Mount Sinai Hospital and hospitals within the province of Ontario, Canada. Due to the paucity of patient-level sociodemographic data collected within health systems, the degree to which the sociodemographic characteristics of this sample is reflective of medical patients cared for within and beyond hospitals in Toronto also remains unclear. Therefore, assessing the generalisability of our findings represents a key opportunity for future research.

Data collection and analysis methods helped reduce the likelihood of traditionally disadvantaged populations being excluded from this study. First, multilingual surveyors and interpreters were available to administer the survey with patients who were unable to participate in English. Research staff were also specially trained in the administration of surveys for sensitive information. To prevent people who were uncomfortable or unable to respond to certain questions from being excluded during multivariable regression analyses, PNA and DK responses were aggregated into a single category and modelled. Differing proportions of missing data across sociodemographic variables may have increased risk of type two error within multivariable model results. Caution should thus be exercised when interpreting our results particularly in relation to income within this sample. However, since the hazard ratio confidence intervals were relatively consistent in range across variables, we do not believe type two error likely accounts for differences in results between the factors examined.

\section{CONCLUSION}

While attentiveness to people's sociodemographic circumstances is an important component of patientcentred care, in our study, patient-level sociodemographic factors did not substantially influence risk of unplanned readmission within 30 days. Need factors indicating illness level, namely, frequency of previous hospitalisation, were however associated with readmission. These findings are important as clinicians consider among whom and how to intervene to prevent readmissions, and health system administrators consider how to measure readmissions to promote quality improvement. Future research should examine the generalisability of our findings within and beyond Toronto, Canada, and investigate whether contextual factors, such as access to universal health insurance coverage, attenuate the effects of sociodemographic factors.

\section{Author affiliations}

${ }^{1}$ Nuffield Department of Population Health, University of Oxford, Oxford, UK ${ }^{2}$ Institute of Health Policy, Management and Evaluation, University of Toronto, Toronto, Ontario, Canada

${ }^{3}$ Bridgepoint Collaboratory for Research and Innovation, Bridgepoint Active Healthcare, Toronto, Ontario, Canada

${ }^{4}$ Department of Health Research Methods, Evidence, and Impact, McMaster University, Hamilton, Canada

${ }^{5}$ Department of Medicine, University of Toronto, Toronto, Canada

${ }^{6}$ Department of Medicine, Sinai Health System and University Health Network, Toronto, Ontario, Canada

${ }^{7}$ Dalla Lana School of Public Health, University of Toronto, Toronto, Ontario, Canada ${ }^{8}$ Institute of Clinical Evaluative Sciences, Toronto, Canada

${ }^{9}$ Department of Medicine, University of Ottawa, Ottawa, Canada

${ }^{10}$ Ottawa Hospital Research Institute, The Ottawa Hospital, Ottawa, Ontario, Canada ${ }^{11}$ Lawrence S. Bloomberg Faculty of Nursing, University of Toronto, Toronto, Ontario, Canada

Contributors RWS was responsible for study design, data analysis, interpretation of results and manuscript production. KK, APC, SKS and LJ advised RWS on study design and analysis. RWS and SKS facilitated data acquisition. All authors contributed to data interpretation, critically revised the manuscript, approved the final submission and act as guarantors of this work.

Funding RWS received funding through the Canadian Institutes of Health Research Canada Graduate Scholarship, a Mount Sinai Hospital Department of Medicine Graduate Studentship and through grant funding awarded to LJ from the Ontario Ministry of Health and Long Term Care. RG was supported as a Clinician 
Scientist in the Department of Family and Community Medicine at the University of Toronto and at St Michael's Hospital.

Competing interests None declared.

Patient consent Detail has been removed from this case description/these case descriptions to ensure anonymity. The editors and reviewers have seen the detailed information available and are satisfied that the information backs up the case the authors are making.

Ethics approval Primary data collection and analyses were approved by the Mount Sinai Hospital Research Ethics Board (REB Number: 11-0319-E).

Provenance and peer review Not commissioned; externally peer reviewed. Data sharing statement № additional data are available.

Open Access This is an Open Access article distributed in accordance with the Creative Commons Attribution Non Commercial (CC BY-NC 4.0) license, which permits others to distribute, remix, adapt, build upon this work non-commercially, and license their derivative works on different terms, provided the original work is properly cited and the use is non-commercial. See: http://creativecommons.org/ licenses/by-nc/4.0/

(C) Article author(s) (or their employer(s) unless otherwise stated in the text of the article) 2017. All rights reserved. No commercial use is permitted unless otherwise expressly granted.

\section{REFERENCES}

1. Canadian Institute for Health Information. All-cause readmission to acute care and return to the emergency department. Ottawa, Canada: Canadian Institute for Health Information, 2012.

2. Jencks SF, Williams MV, Coleman EA. Rehospitalizations among patients in the Medicare fee-for-service program. $N$ Engl J Med 2009;360:1418-28.

3. van Walraven $C$, Jennings A, Taljaard M, et al. Incidence of potentially avoidable urgent readmissions and their relation to all-cause urgent readmissions. CMAJ 2011;183:E1067-72.

4. Dharmarajan K, Krumholz HM. Risk after hospitalization: we have a lot to learn. J Hosp Med 2015;10:135-6.

5. van Walraven C, Dhalla IA, Bell C, et al. Derivation and validation of an index to predict early death or unplanned readmission after discharge from hospital to the community. CMAJ 2010;182:551-7.

6. van Walraven C, Wong J, Forster AJ. LACE+ index: extension of a validated index to predict early death or urgent readmission after hospital discharge using administrative data. Open Med 2012;6:80-90.

7. Ontario HQ. Canadian Institute for Health Information. Early identification of people at-risk of hospitalization: Hospital Admission Risk Prediction (HARP) - a new tool for supporting providers and patients. Toronto, Canada: Queen's Printer of Ontario, 2013

8. Donzé J, Aujesky D, Williams D, et al. Potentially avoidable 30-day hospital readmissions in medical patients: derivation and validation of a prediction model. JAMA Intern Med 2013;173:632-8.

9. O'Connor M, Murtaugh CM, Shah S, et al. Patient characteristics predicting readmission among individuals hospitalized for heart failure. Med Care Res Rev 2016;73:3-40.

10. Kansagara $D$, Englander $\mathrm{H}$, Salanitro $\mathrm{A}$, et al. Risk prediction models for hospital readmission: a systematic review. JAMA 2011;306:1688-98.

11. Calvillo-King L, Arnold D, Eubank KJ, et al. Impact of social factors on risk of readmission or mortality in pneumonia and heart failure: systematic review. J Gen Intern Med 2013;28:269-82.

12. Hasan O, Meltzer DO, Shaykevich SA, et al. Hospital readmission in general medicine patients: a prediction model. $J$ Gen Intern Med 2010;25:211-9.

13. van Walraven C, Wong J, Forster AJ. Influence of neighborhood household income on early death or urgent hospital readmission. J Hosp Med 2013;8:261-6.

14. García-Pérez L, Linertová R, Lorenzo-Riera A, et al. Risk factors for hospital readmissions in elderly patients: a systematic review. QJM 2011;104:639-51.

15. Mudge AM, Kasper K, Clair A, et al. Recurrent readmissions in medical patients: a prospective study. J Hosp Med 2011;6:61-7.

16. Fleming LM, Gavin M, Piatkowski G, et al. Derivation and validation of a 30-day heart failure readmission model. Am J Cardiol 2014;114:1379-82.
17. Hu J, Gonsahn MD, Nerenz DR. Socioeconomic status and readmissions: evidence from an urban teaching hospital. Health Aff 2014;33:778-85.

18. Mather JF, Fortunato GJ, Ash JL, et al. Prediction of pneumonia 30-day readmissions: a single-center attempt to increase model performance. Respir Care 2014;59:199-208.

19. Coventry PA, Gemmell I, Todd CJ. Psychosocial risk factors for hospital readmission in COPD patients on early discharge services: a cohort study. BMC Pulm Med 2011;11:49.

20. McGregor MJ, Reid RJ, Schulzer M, et al. Socioeconomic status and hospital utilization among younger adult pneumonia admissions at a Canadian hospital. BMC Health Serv Res 2006;6:1-10.

21. Karliner LS, Kim SE, Meltzer DO, et al. Influence of language barriers on outcomes of hospital care for general medicine inpatients. J Hosp Med 2010:5:276-82.

22. Peterson PN, Campagna EJ, Maravi M, et al. Acculturation and outcomes among patients with heart failure. Circ Heart Fail 2012;5:160-6.

23. Watson AJ, O'Rourke J, Jethwani K, et al. Linking electronic health record-extracted psychosocial data in real-time to risk of readmission for heart failure. Psychosomatics 2011;52:319-27.

24. Ketterer MW, Draus C, McCord J, et al. Behavioral factors and hospital admissions/readmissions in patients with $\mathrm{CHF}$. Psychosomatics 2014;55:45-50.

25. van Oeffelen AA, Agyemang C, Stronks K, et al. Prognosis after a first hospitalisation for acute myocardial infarction and congestive heart failure by country of birth. Heart 2014;100:1436-43.

26. Andersen RM, Davidson PL. Chapter 1: Improving access to care in america-individual and contextual indicators. In: Andersen RM, Rice TH, Kominski GF, eds. Changing the US health care system: key issues in health services policy and management. 3rd edn. San Francisco: Jossey-Bass, 2007:3-31.

27. Kirst M, Shankardass K, Bomze S, et al. Sociodemographic data collection for health equity measurement: a mixed methods study examining public opinions. Int J Equity Health 2013;12:75-10.

28. Wray R, Agic B, Bennett-AbuAyyash C, et al. We ask because we care: The Tri-Hospital + TPH Health Equity data collection research project report. Mount Sinai Hospital Toronto, Canada, 2013.

29. Mount Sinai Hospital and Toronto Central Local Health Integration Network. Measuring health equity. 2016. http://torontohealthequity. $\mathrm{ca} /$

30. Canadian Institute for Health Information. Technical note: 30-day adult medical readmission rate. Canada: Canadian Institute for Health Information, 2015.

31. Smith RW. Patient-level social determinants of unplanned hospital readmission among general internal medicine patients. Toronto, Canada: University of Toronto, 2016.

32. Statistics Canada. Same-sex couples and sexual orientation. The Daily: By the numbers. 2016. http://www.statcan.gc.ca/eng/dai/ smr08/2015/smr08 2032015

33. Quan H, Li B, Couris CM, et al. Updating and validating the Charlson comorbidity index and score for risk adjustment in hospital discharge abstracts using data from 6 countries. Am J Epidemiol 2011;173:676-82.

34. Fitzpatrick T, Rosella LC, Calzavara A, et al. Looking beyond income and education: socioeconomic status gradients among future highcost users of health care. Am J Prev Med 2015;49:161-71.

35. SAS Institute Inc. SAS. Version 9.4. Cary, NC: SAS Institute Inc. 2012.

36. Allaudeen $\mathrm{N}$, Vidyarthi $\mathrm{A}$, Maselli J, et al. Redefining readmission risk factors for general medicine patients. J Hosp Med 2011;6:54-60.

37. Lanièce I, Couturier $P$, Dramé $M$, et al. Incidence and main factors associated with early unplanned hospital readmission among French medical inpatients aged 75 and over admitted through emergency units. Age Ageing 2008;37:416-22.

38. Meyers AG, Salanitro A, Wallston KA, et al. Determinants of health after hospital discharge: rationale and design of the vanderbilt inpatient cohort study (VICS). BMC Health Serv Res 2014;14:10.

39. Kahlon S, Pederson J, Majumdar SR, et al. Association between frailty and 30-day outcomes after discharge from hospital. CMAJ 2015;187:799-804.

40. Greysen SR, Stijacic Cenzer I, Auerbach AD, et al. Functional impairment and hospital readmission in Medicare seniors. JAMA Intern Med 2015;175:559-65.

41. National Academies of Sciences Engineering and Medicine. Accounting for social risk factors in medicare payment: Identifying social risk factors. Washington, DC: The National Academies Press, 2016.

42. Forum NQ. Risk adjustment for socioeconomic status or other sociodemographic factors. Washington, DC: National Quality Forum, 2014 